\title{
The limbus reflection method for measuring eye position
}

\author{
J. EDWARD RUSSO \\ University of California, San Diego, La Jolla, California 92037
}

\begin{abstract}
Eye position can be measured by reflecting light off the iris-scleral limbus. This method provides at least $1 / 2$ deg accuracy over a range of $30 \mathrm{deg}$ horizontally and $20 \mathrm{deg}$ vertically. The limbus reflection method usually requires that the subject's head be held rigid by a bite plate. The method offers the advantages of costing less than most other techniques and of conveniently interfacing with a laboratory computer for automated data reduction. Limbus reflection sensors have been constructed at over a dozen different laboratories, and one apparatus is available commercially. Not all implementations have reached the attainable accuracy and range, especially for eye movements in the vertical direction.
\end{abstract}

The sequence of eye fixations exhibited during the performance of a cognitive task can be an important source of process tracing data. In order to collect such data, eye direction must be continuously and accurately measured, and the resulting signals must be efficiently reduced to a sequence of eye fixations. The limbus reflection method is one of several techniques for measuring eye direction with sufficient accuracy. This method conveniently interfaces with a digital computer for efficient reduction of the raw eye position signals to a sequence of fixation locations and durations.

The purpose of this paper is to present the operating principles of the limbus reflection method and to evaluate the various implementations of those principles. This paper concludes with an analysis of the advantages and limitations of the method.

\section{PRINCIPLES OF OPERATION}

The limbus reflection method takes advantage of the different reflectances of the iris (colored) and sclera (white) and of the sharp limbus (border) between them. To see how the different reflectances can be used to track eye position, consider the pattern of illuminated rectangles shown in Figure 1. On the schematic diagram of the left eye are the two lights used to detect horizontal position. When the eye is aimed straight ahead (as shown), a baseline of the energy reflected from each illuminated rectangle is measured by two photodiodes. Now consider what happens to both signals as the eye moves to its own right. The iris moves toward the left rectangle, diminishing the reflected light. Similarly, more of the right rectangle falls on highly reflecting sclera, causing an increased signal. Since the two signals change in opposite directions, their difference indicates horizontal eye position. The

This research was supported by Grant MH24880 from the National Institutes of Health. Requests for reprints may be sent to the author, Department of Psychology, University of California, San Diego, La Jolla, California 92037.
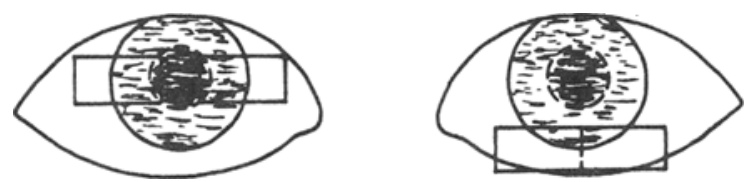

Figure 1. Pattern of illuninated rectangles for measuring horizontal (left) and vertical (right) eye position.

recorded signal tracks eye position accurately because both the iris and sclera provide relatively uniform reflectance and because the limbus is sharply defined. Since each photosensor is actually recording the position of the iris-scleral limbus, this method is also called limbus tracking (Young \& Sheena, 1975).

In order to provide independence from vertical eye movements, two rectangles are used. As the eye moves upward (or downward) from the position shown on the left in Figure 1, the reflected energy of both rectangles increases. By using the difference between the left and right signals, the effect of vertical movements is eliminated.

The pattern of rectangles for measuring vertical position is shown on the right in Figure 1. Two rectangles are aimed at the bottom of the iris-scleral limbus so as to form a continuous bar. The total reflected energy is detected by a single sensor. As the eye moves upward, the recorded signal increases, while a downward movement reduces the reflected energy. Because the lighted bar is extended to the right and left of center, horizontal changes do not affect the vertical signal.

The limbus reflection method almost always uses infrared light. In this way, a subject's vision is not impaired by the illumination pattern shown in Figure 1. An infrared source is usually constructed by filtering an incandescent source, with the filter removed to enable the initial alignment of the rectangles. Similarly, the photoelectric sensors respond only to infrared radiation. Thus, the recorded signal can be relatively free of changes in (noninfrared) ambient room light, especially 
changes caused by the varying luminance of the stimulus display. If greater independence of ambient light levels is required, the light sources can be pulsed at a given frequency and the photosensors made responsive to only that frequency.

\section{VARIOUS IMPLEMENTATIONS}

The first use of the limbus reflection method was by Torok, Guillemin, and Barnothy in 1951. They relied on a single bar of light to measure each of horizontal and vertical position. Richter (1956) was the first to use the differential principle, illustrated on the left of Figure 1, for recording horizontal movements independent of vertical ones. The method was then rediscovered by Smith and Warter $(1959,1960)$ and by Rashbass $(1960)$. A commercial apparatus (Biometrics Division, NARCO Bio-Systems, Inc., Houston, Texas) was built by Young in 1963 and modified in 1970. This is the only apparatus based on the limbus reflection principle that is commercially available. Over the last 15 years, other devices have been constructed by Findlay (1974), Gaarder, Silverman, Pfefferbaum, Pfefferbaum, and King (1967), Mitrani, Yakimoff, and Mateeff (1972), O'Meara (1966), Stark, Vossius, and Young (1962), Vladimirov and Homskaya (1969), Wheeless, Boynton, and Cohen (1966), Young (1970); Feinstein (Note 2), Noton (Note 4), Russo \& Mathews (Note 5), Zuber (Note 6).

Although all these devices rely on the principles described above, there are important differences in technique. For example, the illuminated rectangles may be arranged differently from the pattern depicted in Figure 1. Jones (1973) measures both horizontal and vertical position from two rectangles that are arranged radially across the limbus at $225 \mathrm{deg}$ and $315 \mathrm{deg}$. Vertical position can be detected from the pupil-iris boundary (Wheeless et al., 1966) or from eyelid movements (Mitrani et al., 1972; Young, 1970) which are known to be closely related to vertical eye movements (McEwen \& Goodner, 1969). The rectangles that shape the beam of light may mask the sensor rather than the source (Jones, 1973; Wheeless et al., 1966). Some devices use no shaping of the light sources at all (Stark et al., 1962; Noton, Note 4). The infrared light may be produced either by filtering an incandescent source or from light-emitting diodes (LEDs). In addition to these differences, each apparatus typically has a different mechanical design for aiming the sources and sensors and different electronics for processing the initial signals.

The differences in design of a limbus reflection apparatus can markedly affect operating convenience. For example, LEDs are far superior light sources because they are uniform in intensity and give off very little heat (minimizing variations in temperature sensitive components). The development of a LED (GE, Part
No. SSL-3) that has an emission peak in the visible range as well as in the infrared permits a conventional alignment procedure as well as infrared operation.

The pattern of lights is critical for several reasons. First, the range of measurable eye movement is directly related to the configuration of the rectangles. When the limbus moves beyond an illuminated rectangle, further movement will produce no signal changes. Yet, if the rectangles are extended too far, they will overlap the eyelids and other structures. The location of the rectangles for vertical measurement is particularly sensitive. The orientation shown on the right in Figure 1 was arrived at after considerable experimentation (Russo $\&$ Mathews, Note 5). For some subjects, vertical position cannot be measured without overlapping the lower eyelid. A long rectangular bar was found to be relatively tolerant of eyelid movements. For all limbus reflection devices, horizontal movements are measured more conveniently and over a wider range than are vertical eye movements. Finally, a poor configuration of lights can create "crosstalk," usually a failure of the vertical and horizontal signals to be independent of each other. Designs that must take both signals off the same reflected light are particularly vulnerable to crosstalk. The design shown in Figure 1 avoids this problem because it measures only one direction from each eye. A different kind of crosstalk can occur when faulty alignment results in one horizontal sensor detecting the reflected energy from the opposite illuminated rectangle.

\section{PERFORMANCE}

The most important performance criterion is accuracy, which refers to the range of recorded positions over repeated fixations of the same point. Thus, an accuracy of $1 \mathrm{deg}$ means that repeated fixations should register within a $1-\mathrm{deg}$ range. This criterion should not be confused with resolution (or sensitivity) which refers to the smallest change in eye position that can be reliably detected. For most experiments in cognitive psychology, an accuracy of $1 / 2$ deg is sufficient. Greater accuracy is often not meaningful because the width of the fovea (about $2 \mathrm{deg}$ ) permits a $1 / 2$-deg range of fixation location (Rashbass, 1961). When stimulus components are separated so as to eliminate peripheral processing, accuracies of $1 \mathrm{deg}$ or even $2 \mathrm{deg}$ may be sufficient. On the other hand, accuracies in excess of $1 / 2$ deg may be necessary for certain natural stimulus material, such as text, photographs of terrain, x-rays, and art.

The accuracy of most limbus reflection devices reaches the $1 / 2$-deg criterion, at least for horizontal position. The measurement of vertical position is more difficult, although $1 / 2$-deg accuracy can be obtained. The commercial apparatus by Biometrics does not provide adequate vertical accuracy. The resolution of most 
limbus reflection devices is excellent. Several versions have reported resolutions of only a few minutes of arc [Findlay (1974), Gaarder et al. (1967), Jones (1973), O'Meara (1966), Wheeless et al. (1966); Zuber (Note 6)].

The main sources of inaccuracy are head movements, electrical and mechanical drift, and nonlinearities. Head movements relative to the apparatus cannot be distinguished from rotations of the eye (without additional equipment). For this reason, the head is usually fixed to a rigid bite plate (Findlay, 1969). Even a head movement as small as $.2 \mathrm{~mm}$ can simulate a rotation of $1 \mathrm{deg}$. Thus, the actual accuracy will depend upon the quality of the head restraint, including the subject's cooperation in maintaining a firm grip on a bite plate. The errors that result from head movements are often, but not always, detectable. Even then, searching for them requires an otherwise unnecessary hand analysis of the data.

The problem of signal drift is idiosyncractic to the mechanical and electrical design of each apparatus. In my own equipment, I have experienced some electronic drift due to temperature-sensitive components. The drift is easily corrected by rezeroing the horizontal and vertical offsets. Nonlinearities in the recorded signal are usually small (about 5\%). Furthermore, if the sensed eye positions are computer analyzed, even these nonlinearities can be removed by a suitable software system (e.g., Reder, 1973).

The overall accuracy of the limbus reflection method is satisfactory for most experimental needs. Devices that attain accuracies of better than $1 / 2 \mathrm{deg}$ on both vertical and horizontal are well within the current state of the art. As laboratory computers become more common and as the quality of electronic components improves, the only important source of errors will be head movements. This problem is not unique to the limbus reflection method, but it is worth noting that it is the limiting factor on accuracy.

\section{ADVANTAGES AND LIMITATIONS}

The limbus reflection technique has several advantages that recommend it as a general purpose eye sensing method. First, it provides good accuracy $(1 / 2 \mathrm{deg})$ over a range of $30 \mathrm{deg}$ horizontal and $20 \mathrm{deg}$ vertical. This is sufficient for almost all applications.

Just as important, limbus reflection devices tend to be reliable and simple to operate. First, there are no complicated or sensitive optics. Second, because the output is analog, an automated data reduction procedure can be used (Loftus, Mathews, Bell, \& Poltrock, 1975). There is no need for a laborious hand analysis of photographs. Finally, because the initial signal is optical, the problems associated with biopotentials can be avoided (Senders, 1975). The main operating problem is typically the initial alignment and calibration. A little practice, however, usually reduces this time to an acceptable level, about $5 \mathrm{~min}$ in my experience.
A limbus reflection sensor may be purchased for only a few thousand dollars. A copy of an existing device can be constructed at even less expense, about $\$ 1,000$, including parts and labor (Jones, 1973; Russo \& Mathews, Note 5). These cost estimates include only the sensor and not an apparatus for recording and analyzing the sensed eye positions. The cost of the limbus reflection method is lower than that of almost any other method and is much lower than the (approximately) $\$ 20,000$ cost of the most recently developed methods (Young \& Sheena, 1975). Because the limbus reflection method is primarily electronic rather than optical, the development of better and cheaper devices can be expected. Limbus reflection devices should enjoy the benefits of the increased quality, miniaturization, and cost reductions that characterize the electronics industry.

Finally, the limbus reflection method is able to interface conveniently with a laboratory computer. One of the main barriers to the collection of eye movements is the task of reducing raw eye positions to sequences of fixations and durations. The laboratory computer removes this barrier for sensed eye positions that are computer compatible, as is a voltage that can be analog-to-digitally converted. A second advantage of convenient computer interfacing is the possibility of using the eye fixations to generate novel data. For example, the eye fixations can provide on-line control of the stimulus display [Gourlay, Gyr, Walters, \& Willey (1975), Reder (1973); McConkie \& Rayner (Note 3)] or can be replayed to prompt a retrospective verbal protocol [Conery, Smith, \& Russo (Note 1)]

The limbus reflection method has limitations on its applicability. The apparatus I have described is suitable only for fixed-head, fixed-field situations. Neither of these limitations is inherent in the sensing method, but this technique does not make it easy to get around them. The fixed head requirement can be removed by fixing the sensors to the head, usually through a helmet or eyeglass frame. If this is done, the direction of regard must be related to the field of view by separately recording the field relative to the head. A head-mounted video sensor accomplishes this and permits a moving field as well (Mackworth \& Mackworth, 1958). Alternately, one can detect head movements relative to a fixed field. Young and Sheena (1975) review such methods.

The alignment and calibration requirements of a limbus reflection apparatus are modest. Making a bite plate for each subject, however, discourages the use of large numbers of subjects for only a few minutes each. The need to maintain a firm grip on the bite plate makes this technique unsuitable for young children. Finally, the accuracy of about $1 / 2$ deg may not be sufficient for all cognitive tasks. This is especially true of tasks with important perceptual components, such as photo-interpretation, $\mathrm{x}$-ray diagnosis, and inspection for quality control. 


\section{REFERENCE NOTES}

1. Conery, J. S., Smith, R. T., \& Russo, J. E. Interactive experimental techniques. Proceedings of the Fall DECUS Symposium, San Diego, 1974.

2. Feinstein, $R$. Interactions of the horizontal and vertical eye movement systems. Unpublished doctoral dissertation, The University of Michigan, 1970.

3. McConkie, G. W., \& Rayner, K. Identifying the span of the effective stimulus in reading. Research Report No. 3, Reading and Learning Series, Department of Education, Cornell University, 1974.

4. Noton, D. Two models of the brain, with applications to artificial intelligence. Unpublished doctoral dissertation, University of California, Berkeley, 1970.

5. Russo, J. E., \& Mathews, P. Tracking eye fixations. Unpublished manuscript, University of California, San Diego, January, 1975.

6. Zuber, B. L. Physiological control of eye movements in humans. Unpublished doctoral dissertation, Massachusetts Institute of Technology, 1965 .

\section{REFERENCES}

Findlay, J. M. The magnitude of translational head movements Optica Acta, 1969, 16, 65-68.

Findlay, J. M. A simple apparatus for recording microsaccades during visual fixation. Journal of Experimental Psychology, 1974, 26, 167-170.

Gaarder, K., Silverman, J., Pfefferbaum, D., Pfefferbaum, L., \& $\mathrm{King}, \mathrm{C}$. Infrared method for assessment of small and large eye movements in clinical experiments. Perceptual and Motor Skills, 1967, 25, 473-484.

Gourlay, K., Gyr, J. W. Walters, S., \& Wîley, R. Instrumentation designed to simulate the effects of prisms used in studies of visual management. Behavior Research Methods \& Instrumentation, 1975 , in press.

Jones, R. Two dimensional eye movement recording using a photoelectric matrix method. Vision Research, 1973, 13, $425-431$.

Loftus, G. R., Mathews, P., Bell, S., \& Poltrock, S. General software for an on-line eye movement recording system. Behavioral Research Methods \& Instrumentation, 1975, in press.

Mackworth, F. J.. \& Mackworth, N. H. Eye fixations recorded on changing visual scenes by the television eye marker. Journal of the Optical Society of America, 1958, 48, 439-445.
McEwen, W. K., \& Goodner, E. K. Secretion of tears and blinking. In $\mathrm{H}$. Davson (Ed.), The eye (Vol. 3). New York: Academic Press, 1969.

Mitrani, L., Yakimoff, N., \& Mateeff, St. A combined photoelectric method for detecting eye movements. Vision Research, 1972, 12, 2145-2146.

O'Meara, D. Photoelectric eye movement detector. Proceedings of the 19th Annual Conference on Engineering in Medicine and Biology, 1966, 241.

Rashbass, C. New method for recording eye movements, Journal of the Optical Society of America, 1960, 50, 642-644.

Rashbass, C. The relationship between saccadic and smooth tracking eye movements. Journal of Physiology, 1961, 159 326-333.

Reder, $S$. M. On-line monitoring of eye position signals in contingent and non-contingent paradigms. Behavioral Research Methods \& Instrumentation, 1973, 5, 218-228.

Richter, H. R. Principes de la photo electronystagmographie. Revue Neurologique, 1956, 94, 138-141.

Senders, J. W. Characteristics and limitations of electro-ocular recording. Behavioral Research Methods \& Instrumentation, 1975 , in press.

Smith, W. M., \& Warter, P. J., Jr. Photoelectric technique for measuring eye movements. Science, 1959, 130, 1248-1249.

Smith, W. M., \& Warter, P. J., Jr. Eye movement and stimulus movement: New photoelectric electromechanical system for recording and measuring tracking motions of the eye. Joumal of the Optical Society of America, 1960,50, 245-250.

Stark, L., Vossius, G., \& Young, L. R. Predictive control of eye tracking movements. IRE Transactions on Human Factors in Electronics, 1962, 3, 52-57.

Torok, N., Gullemin, V.. Jr., \& Barnothy, J. M. Photoelectric nystagmography. Annals of Oto-Rhino and Laryngology. $1951,60,917-926$.

Vladimirov, A. D., \& Homskaya, E. D. Photoelectric methods of recording eye movements. American Psy chologist, 1969, 24, 214-218.

Wheeless, L. L., Jr., Boynton, R. M., \& Cohen, G. H Eye-movement response to step and pulse stimuli. Journal of the Optical Society of America, 1966, 56, 956-960.

Young, L. R. Measuring eye movements. American Joumal of Medical Electronics, 1963, 2, 300-307.

Young, L. R. Recording eye position. In M. Clynes and J. H. Milsum (Eds.), Biomedical Engineering Systems. New York: McGraw-Hill, 1970 .

Young, L. R., \& Sheena, D. Survey of eye movement recording methods. Behavioral Research Methods \& Instrumentation, 1975 , in press. 